\title{
Comparing two "thermometers": \\ Impact factors of 20 leading economic journals according to \\ Journal Citation Reports and Scopus
}

\author{
VLADIMIR PISLYAKOV \\ Higher School of Economics, Library, Moscow (Russia)
}

Impact factors for 20 journals ranked first by Journal Citation Reports (JCR) were compared with the same indicator calculated on the basis of citation data obtained from Scopus database. A significant discrepancy was observed as Scopus, though results differed from title to title, found in general more citations than listed in JCR. This also affected ranking of the journals. More thorough examination of two selected titles proved that the divergence resulted mainly from difference in coverage of two products, although other important factors also play their part.

\section{Introduction}

Citation indexes from Thomson Scientific (former Institute for Scientific Information, ISI) integrated into Web of Science (WoS) online product as well as their bibliometric counterpart Journal Citation Reports (JCR) database serve for years to scientists, scientometrists and science administrators. Recently another large citation index database emerged from Elsevier, product named Scopus. It was taken by library and scientometric communities as a major WoS competitor and a number of comparative studies were published (for example, JACSO, 2004; JACSO, 2005; LAGUARDIA, 2005; ROTH, 2005; BAKKALBASI et al., 2006; LIBMANN, 2007). The latest paper of DE MOYA-ANEGON et al. (2007) compares Scopus database against the Ulrich's Periodical Directory while BAR-ILAN et al. (2007) examine rankings of the papers derived from citations they receive according to different citation tools, WoS and Scopus included. 
Impact factor (IF) as a journal citation measure has become widely spread since its introduction by GARFIELD \& SHER (1963). Though there is a continuous discussion about its shortcomings or potential for abuse (e.g. GLÄNZEL, 2002; ROUSSEAU, 2002; PISLYAKOV, 2007), one hardly could deny a strong influence of this indicator on the contemporary scientometric field. Impact factors are calculated by Thomson Scientific and delivered each year through JCR database.

Scopus does not calculate any citation parameter similar to IF, because its developers rather prefer to rely on another indicator, h-index proposed by HIRSCH (2005). However, there is no fundamental impossibility to evaluate journal IF from the Scopus data. IF for the journal $\mathrm{J}$ for the year $\mathrm{Y}$ is defined as a number of citations that papers published in $\mathrm{J}$ during years $\mathrm{Y}-1$ and $\mathrm{Y}-2$ receive in year $\mathrm{Y}$, divided by the number of these papers. All these variables can be got by appropriate searches conducted in Scopus. A distinctive feature here is that we explicitly obtain the papers which cite $J$ and which references influence the J's IF, while JCR displays number of cites for each journal, but does not list exactly what items those citations came from.

In this paper we aim to calculate IFs from the Scopus database for 20 journals top-ranked by JCR in subject category "Economics" and compare them with the JCR impacts. If the inequality of impacts is observed, it is expected to be explained mainly by difference between coverage of WoS and Scopus. Consequently, this juxtaposition will, on the one hand, demonstrate some characteristics of both products (for example, breadth of coverage in economics field and accuracy of citation identification by each database), on the other hand reveal properties of the impact factor itself, its stability or instability with respect to the database used. Special attention will be given to the change of journal rankings which may proceed from the change of impacts. Recently MEHO \& YANG (2007) studied the effect of using Scopus on the rankings of LIS faculty members and found it to be significant.

For our purpose 2005 Social Sciences edition of JCR will be used. This product lists impact factors as well as other bibliometric indicators for 1747 journals, 175 of them are placed into Economics subject category. Since June 2007 newer, 2006 impact factors are available through JCR, but dealing with older indicators seems to be reasonable in order to avoid in the process of comparison minor changes of recent content that may occasionally happen in such young and developing database as Scopus. As for Scopus, its title list had 15628 currently active sources as 
of April 2007 with 264 of them in "Economics, Econometrics and Finance" primary category. 252 of these sources are journals.

\section{Methodology}

In Scopus interface each of the 20 titles was entered as a phrase search term into the Source Title field and Date Range limiters were set at 2003-2004. On search results screen the number of papers for this date range was collected (sometimes additional filtering by source name was required to separate such titles as Journal of Health Economics from Health Economics data) and after that all the results were selected and directed to a special Scopus tool "Citation tracker" which enables a user to get number of citations received by a group of documents in any particular year. The figure for the 2005 is taken as a numerator for the impact factor while number of articles is a denominator. Thus Scopus IF column of the Table 1 is calculated.

JCR allows users to obtain impact factors directly from its interface. Still, to compare between two databases the numbers of papers and citations for every title, we used detailed journal information links. There one can find number of "citable items" published in 2003-2004 and number of cites received by them in 2005. These figures as well as their ratio are placed into Table 1 in JCR columns.

Scopus content is still somewhat fluent and subject to change as some of its gaps are being filled until now. That is why it is important to note that all searches were conducted during 10-16 May 2007. As for Thomson Scientific, its JCR is a fixed product and its data may be reproduced at any time from 2005 edition of JCR.

Another important detail must be stressed. JCR takes as a denominator for IF not the number of

all papers, but only that of "citable items" which comprise Article and Review types of papers. We also have to keep this in mind when comparing results obtained from both databases. 
Table 1. Publication, citation data and impact factors for 20 leading economic journals according to JCR and Scopus (P - papers, 2003-2004; C — number of cites, 2005; IF — impact factor)

\begin{tabular}{|c|c|c|c|c|c|c|}
\hline \multirow{2}{*}{ Title } & \multicolumn{3}{|c|}{ JCR } & \multicolumn{3}{|c|}{ Scopus } \\
\hline & $\mathrm{P}$ & $\mathrm{C}$ & IF & $\mathrm{P}$ & $\mathrm{C}$ & IF \\
\hline Quarterly Journal of Economics & 80 & 382 & 4.775 & 81 & 393 & 4.852 \\
\hline Journal of Economic Literature & 37 & 150 & 4.054 & 41 & 176 & 4.293 \\
\hline Journal of Economic Geography & 45 & 145 & 3.222 & 47 & 150 & 3.191 \\
\hline Journal of Health Economics & 113 & 306 & 2.708 & 118 & 342 & 2.898 \\
\hline Journal of Economic Perspectives & 82 & 216 & 2.634 & 106 & 228 & 2.151 \\
\hline Econometrica & 123 & 323 & 2.626 & 129 & 351 & 2.721 \\
\hline Journal of Economic Growth & 26 & 67 & 2.577 & 26 & 79 & 3.038 \\
\hline Journal of Financial Economics & 135 & 322 & 2.385 & 137 & 393 & 2.869 \\
\hline Journal of Political Economy & 98 & 220 & 2.245 & 100 & 238 & 2.380 \\
\hline $\begin{array}{l}\text { Brookings Papers on Economic } \\
\text { Activity }\end{array}$ & 17 & 36 & 2.118 & 19 & 47 & 2.474 \\
\hline Journal of Risk and Uncertainty & 50 & 105 & 2.100 & 52 & 75 & 1.442 \\
\hline Review of Economic Studies & 85 & 173 & 2.035 & 85 & 206 & 2.424 \\
\hline Health Economics & 172 & 330 & 1.919 & 182 & 419 & 2.302 \\
\hline Journal of Accounting and Economics & 65 & 122 & 1.877 & 76 & 124 & 1.632 \\
\hline American Economic Review & 341 & 616 & 1.806 & 343 & 681 & 1.985 \\
\hline Economic Geography & 37 & 65 & 1.757 & 37 & 71 & 1.919 \\
\hline Journal of International Economics & 117 & 195 & 1.667 & 117 & 254 & 2.171 \\
\hline Journal of Monetary Economics & 127 & 211 & 1.661 & 152 & 253 & 1.664 \\
\hline Journal of Law \& Economics & 46 & 74 & 1.609 & 46 & 57 & 1.239 \\
\hline Feminist Economics & 42 & 67 & 1.595 & 49 & 55 & 1.122 \\
\hline Total & 1838 & 4125 & 2.244 & 1943 & 4592 & 2.363 \\
\hline
\end{tabular}

\section{Results and discussion}

Results are summarized in Table 1 and visualized in Figure 1.

For each journal Scopus lists number of 2003-2004 papers not less than that of JCR. It may be easily explained for, as was mentioned before, JCR counts only "citable items" and excludes some types of papers. 5 of 20 titles have equal numbers of papers in both databases which means that all the content of these journals in 2003-2004 constitute research articles and reviews. What 
is more interesting, even for these titles JCR and Scopus list different number of cites: 1 time JCR figure is bigger, 4 times vice versa.

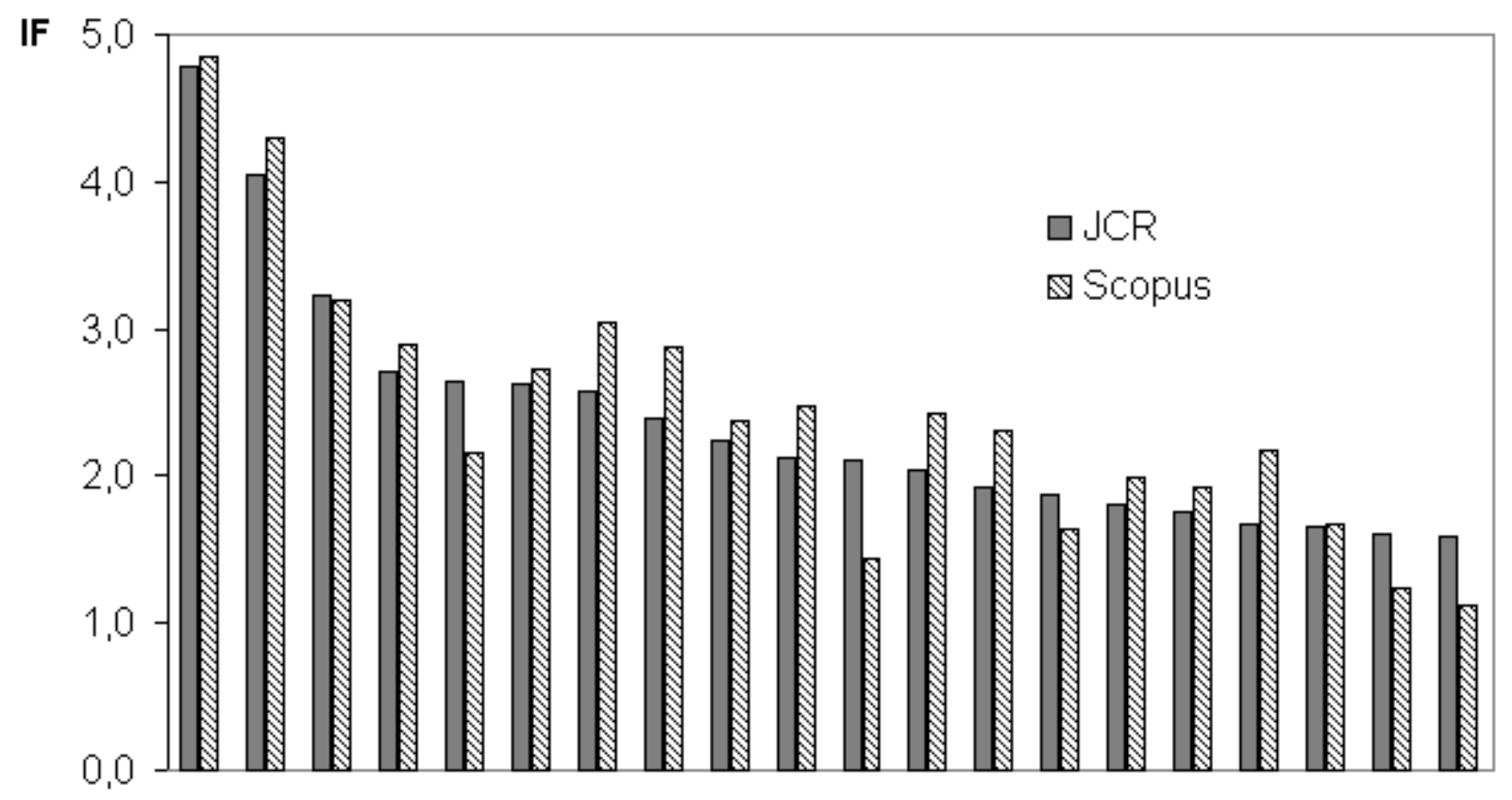

Figure 1. Impact factors of 20 economic journals as taken from JCR and calculated from Scopus

For the whole set of 20 economic journals Scopus finds 5.7\% more papers and $11.3 \%$ more citations. If we consider all these titles as a single unit, as a "macro-journal" (or "meta-journal") in the sense of ROUSSEAU (1988), and find its global impact factor (or weighted average IF) defined as in VAN HOOYDONK et al. (1994) and EGGHE \& ROUSSEAU (1996, 2002), then it would be 2.24 for JCR and 2.36 for Scopus. This means that in general Scopus finds more citations per paper. Median impact for JCR is 2.11, for Scopus 2.34.

Further, for 14 journals out of 20 impact factor based on Scopus data is greater than JCR figures, for 6 journals vice versa. If we sort journals according to Scopus IF, they will notably change their rankings, as shows Figure 2. There are JCR ranks in the left column and Scopus ranks in the right. Arrows show shift of journal positions. We see that three first journals and two last ones do not change their ranks while others move upwards or downwards. The most drastic fall in rank is that of Journal of Economic Perspectives which moves from fifth place to the thirteenth, while the most significant rise is that of Journal of International Economics moving from seventeenth to twelfth position. However, Spearman rank order correlation coefficient for two rankings is 
considerable, 0.86 , proving rather natural fact that two "top lists" are still closely connected to each other. In terms of absolute impact change the leaders are Journal of Risk and Uncertainty $(-0.66)$ and Journal of International Economics $(+0.50)$. The same journals show the most significant relative change of impact with respect to JCR figures, $-31 \%$ and $+30 \%$ respectively. Pearson correlation for two sets of impact factors is also large, 0.93.

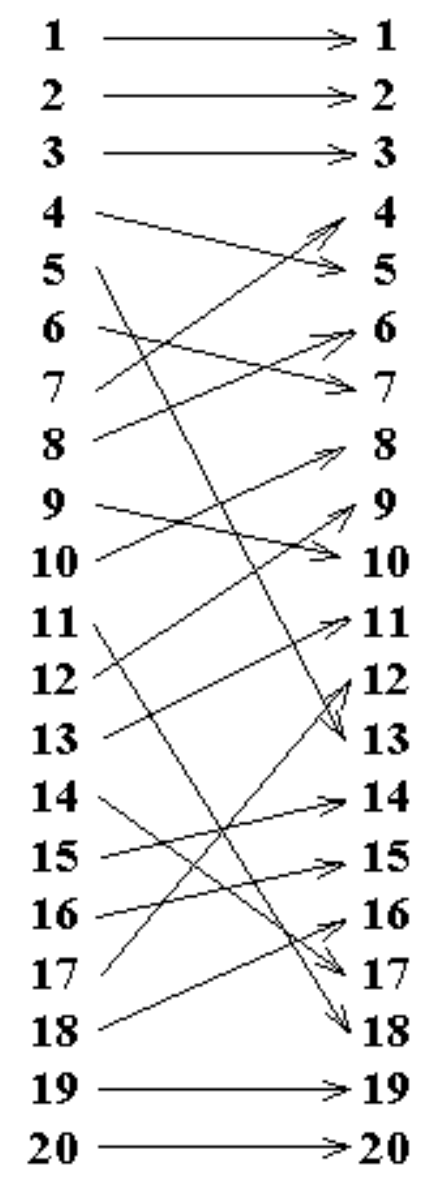

Figure 2. Change in ranking of economic journals after transition from JCR impacts to Scopus.

To discover some factors that lead to the difference of impacts in two databases we chose two journals with significant shift of this index in both directions, Journal of Economic Growth $(+0.46)$ and Journal of Risk and Uncertainty (-0.66), and took a closer look at the reasons for the impact change in each case. The latter is a title with the largest negative change of impact factor while the former ranks third by its rise. However, the first two players are Elsevier titles and this fact, at least in part, may determine their shift. 
As it was said before, one can not find directly from JCR those articles that cite a journal and which citations are counted in journal's impact. For this reason we perform a query in Web of Science for the articles that cite a given journal (supposedly, these citations also account for journal's impact in JCR) and use the same procedure for Scopus. Then we compare two lists of citing articles and examine those of them that do not have a match in another database. Full version and all three components of WoS were used, Science Citation Index Expanded, Social Sciences Citation Index and Arts \& Humanities Citation Index. Where it is necessary, full texts of the citing papers were consulted. Reasons why an item is listed as a citing article in one database and is absent from the other are presented in Table 2.

Table 2. Reasons for absence of a paper from the cited by list in one of the databases

\begin{tabular}{|l|c|c|}
\hline \multicolumn{3}{|c|}{ Items citing Journal of Economic Growth } \\
\hline \multicolumn{1}{|c|}{ Reason } & $\begin{array}{c}\text { Absent from } \\
\text { WoS }\end{array}$ & $\begin{array}{c}\text { Absent from } \\
\text { Scopus }\end{array}$ \\
\hline Citing journal is not indexed by the database & 12 & 4 \\
\hline Reference is incorrect and not recognized by the database & 3 & 1 \\
\hline Database does not extract references from the article & - & 4 \\
\hline The particular issue of the citing journal is missing & 1 & - \\
\hline $\begin{array}{l}\text { The item is present, the reference is correct, but the citation is not } \\
\text { recognized }\end{array}$ & $\mathbf{1 7}$ & $\mathbf{1 2}$ \\
\hline There is really no citation (other database lists it erroneously) & - & 3 \\
\hline Total & 7 & 1 \\
\hline & 1 & 1 \\
\hline Citing journal is not indexed by the database & - & 8 \\
\hline Reference is incorrect and not recognized by the database & - & 3 \\
\hline Database does not extract references from the article & $\mathbf{8}$ & $\mathbf{1 3}$ \\
\hline The particular citing paper is absent though the issue is indexed & & \\
\hline Total & &
\end{tabular}

Some comments on this table. The most usual reasons for the citation's absence are difference of the coverage and inability of the database to decode incorrect reference. One can see that Scopus covers more publications that cite 2003-2004 papers of both journals in 2005 (Appendix lists sources responsible for this effect). Also it is more successful in deciphering inaccurate references that penetrated into the bibliography of scientific works. It may be supposed that Scopus has here an advantage of being developed by a large publisher company which 
presumably holds more detailed information on its articles, because three of the four incorrect references that Scopus identifies while WoS fails to do so are published in Elsevier journals.

Meanwhile the most frequent reason why a citation is missing from Scopus database is absence of all the extracted references for the paper or absence of the paper itself, despite the fact that the corresponding journal is indexed in Scopus. This accounts for 15 out of 22 cases and may be labeled as "the state of the content" factor as they probably reflect the current stage of the development of the young Scopus database.

A rather unexpected effect was noticed when extracting papers that cite Journal of Economic Growth. WoS database lists 3 citations of the 2004 paper by D. Rodrik et al. while in fact it is 2002 preprint of the same authors and with the same title that is cited in the text of all 3 citing papers. This erroneous attribution of the citation we also took into account.

Relative weights of different factors that lead to absence of a citation are summarized in Table 3. Percents are calculated with respect to total 50 cases of the citation error.

Table 3. Role of different factors in missing or erroneous citation (Journal of Economic Growth and Journal of Risk and Uncertainty data)

\begin{tabular}{|l|c|c|}
\hline \multicolumn{1}{|c|}{ Reason } & WoS & Scopus \\
\hline Citing journal is not indexed by the database & $38 \%$ & $10 \%$ \\
\hline Database does not extract references from the article & - & $24 \%$ \\
\hline Reference is incorrect and not recognized by the database & $8 \%$ & $4 \%$ \\
\hline The particular citing paper is absent though the issue is indexed & - & $6 \%$ \\
\hline The particular issue of the citing journal is missing & $2 \%$ & - \\
\hline $\begin{array}{l}\text { The item is present, the reference is correct, but the citation is not } \\
\text { recognized }\end{array}$ & $2 \%$ & - \\
\hline Erroneous citation & $6 \%$ & - \\
\hline
\end{tabular}

\section{Conclusion}

The same citation indicator, impact factor, was obtained for 20 economic journals from two databases, Thomson Scientific's Journal Citation Reports and Elsevier's Scopus. Results were 
compared and found to be not equal to each other. Though total correlation between two sets of impacts was more than 0.9 , for some titles difference in IFs amounted to $30 \%$.

In general Scopus showed higher numbers of cites $(+11.3 \%)$ and higher impacts $(+0.12$ for the mean IF and +0.23 for the median). This is despite the fact that JCR takes not all published papers, but only articles and reviews, when calculates denominator for IF. For each title Scopus showed not less number of papers than JCR and if we correct for this nuance and use JCR's number of papers for IF denominator in both cases then difference will equal 0.25 for the global impact factor of all 20 journals.

We may conclude that Scopus has a broader coverage of the publications that cite leading economic journals. The database would find even more cites if it better followed its own rules, extracted references for all the articles and didn't miss some papers from the issues. This is probably the most marked factor for Scopus, as can be derived from detailed investigation of two journals on the reference by reference level. Its resolution could raise even more the quality of Scopus analytics and make citation characteristics derived from it more accurate.

On the other hand, Web of Science misses citations to the selected journals mainly because of the smaller content coverage. Consequently, there is a complex question on whether WoS should enlarge its list of indexed sources to detect additional cites and how it is to be done without database integrity loss and inclusion of the low quality journals. There is a double-edged issue of how to calculate impact factors on the most complete data set and at the same time not to count citations from peripheral sources on the equal level as from leaders in their fields. We may perhaps suppose that in bibliometrics the importance of weighted measures described, for example, by PINSKY et. al (1976) and tested by BOLLEN et al. (2006) will increase as citation databases will cover more and more source publications.

Finally, the importance of accurate references in periodicals must be stressed one more time, for this proved to be one of the factors that lead to loss of citations and incorrect calculation of IF. This aspect as well as the key role of authors and editors in it was often mentioned by GARFIELD $(1983,1990)$. Our investigation of two journals showed that there are some errors on the side of databases (which sometimes lead even to fictitious citations), but most of such inaccuracies are due to mistakes in papers themselves. 
Since impact factor is considered to be one of the crucial citation indicators which is widely used in research assessment and science administration, it is important to examine it critically from various points of view and investigate the environment in which it is calculated. In the course of such studies a placement of impact factor within the context of different citation databases seems to be quite useful and enlightening. This approach will help us in calibrating our bibliometric "thermometers" to more accurately measure science degrees.

\section{Acknowledgements}

I would like to thank Ekaterina Dyachenko and Vadim Sobolev for their valuable comments on earlier version of this paper.

\section{References}

BAKKALBASI, N., BAUER, K., GLOVER, J., WANG, L. (2006), Three options for citation tracking: Google Scholar, Scopus and Web of Science, Biomedical Digital Libraries, 3. Text available at: http://dx.doi.org/10.1186/1742-5581-3-7

BAR-ILAN, J., LEVENE, M., LIN, A. (2007), Some measures for comparing citation databases, Journal of Informetrics, 1 (1) : 26-34.

BOLLEN, J., RODRIGUEZ, M. A., VAN DE SOMPEL, H. (2006), Journal status, Scientometrics, 69 (3) : 669-687.

DE MOYA-ANEGON, F., CHINCHILlA-RODRIGUEZ, Z., VARGAS-QUESADA, B., CORERA-ALVAREZ, E., MUNOZ-FERNANDEZ, F. J., GONZALEZ-MOLINA, A., HERRERO-SOLANA, V. (2007), Coverage analysis of Scopus: A journal metric approach, Scientometrics, 73 (1) : 53-78.

EGGHE, L., ROUSSEAU, R. (1996), Average and global impact of a set of journals, Scientometrics, 36 (1) : 97-107.

EGGHE, L., ROUSSEAU, R. (2002), A general framework for relative impact indicators, The Canadian Journal of Information and Library Science, 27 : 29-48.

GARFIELD, E. (1983), Quality control at ISI: A piece of your mind can help us in our quest for error-free bibliographic information, Current Contents, $19: 5-12$.

GARFIELD, E. (1990), Journal editors awaken to the impact of citation errors. How we control them at ISI, Current Contents, 41:5-13. 
GARFIELD, E., SHER, I. H. (1963), New Factors in the Evaluation of Scientific Literature through Citation Indexing, American Documentation, 14 (3) : 195-201.

GLÄNZEL, W., MOED, H. F. (2002), Journal impact measures in bibliometric research, Scientometrics, 53 (2) : 171-193.

HIRSCH, J. E. (2005), An index to quantify an individual's scientific research output, Proceedings of the National Academy of Sciences of the United States of America, 102 (46) : 16569-16572.

JACSO, P. (2004), ISI Web of Science, Scopus, and SPORTDiscus, Online, 28 (6) : 51-54.

JACSO, P. (2005), As we may search - comparison of major features of the Web of Science, Scopus, and Google Scholar citation-based and citation-enhanced databases, Current Science, 89 (9) : 1537-1547.

LAGUARDIA, C. (2005), Scopus vs. web of science, Library Journal, 130 (1) : 40-42.

LIBMANN, F. (2007), Web of Science, Scopus, and Classical Online: Philosophies of searching, Online, 31 (3) : 36-40.

MEHO, L. I., YANG, K. (2007), Impact of data sources on citation counts and rankings of LIS faculty: Web of Science versus Scopus and Google Scholar, Journal of the American Society for Information Science and Technology, 58 (13) : 2105-2125.

PINSKY, G., NARIN, F. (1976), Citation influence for journal aggregates of scientific publications: Theory, with application to the literature of physics, Information Processing \& Management, 12 (5) : 297-312.

PISLYAKOV, V. V. (2007), Methods for assessment of scientific knowledge through citation indicators, Sotsiologicheskii Zhurnal, 1 : 128-140 (in Russian).

ROTH, D. L. (2005), The emergence of competitors to the Science Citation Index and the Web of Science, Current Science, 89 (9-10) : 1531-1536.

ROUSSEAU, R. (1988), Citation distribution of pure mathematics journals. In: Informetrics 87/88, EGGHE, L., ROUSSEAU, R., (Eds.), Amsterdam, Elsevier, 249-262.

ROUSSEAU, R. (2002), Journal evaluation: Technical and practical issues, Library Trends, 50 (3) : 418-439.

VAN HOOYDONK, G., GEVAERT, R., MILIS-PROOST, G., VAN DE SOMPEL, H., DEBACKERE, K. (1994), A bibliotheconomic analysis of the impact factors of scientific disciplines, Scientometrics, 30 (1) : 65-81. 


\section{Appendix}

These sources are indexed only either by Scopus or Web of Science and contain citation(s) from their 2005 article(s) to the 2003-2004 issues of Journal of Economic Growth or Journal of Risk and Uncertainty. This leads to the lost citations in another database.

Sources indexed only by Scopus

American Law and Economics Review

Constitutional Political Economy

European Journal of Development Research

European Journal of Political Economy

Intereconomics

International Journal of Comparative Sociology (indexing by WoS discontinued since 2003)

International Journal of Global Environmental Issues

International Relations of the Asia-Pacific

Journal of Accounting and Public Policy (indexing by WoS discontinued since 1996)

Journal of Asian Economics

Journal of International Management

Journal of Real Estate Literature

Labour

Proceedings of the International Conference on Offshore Mechanics and Arctic Engineering OMAE

Research in Transportation Economics

Review of Radical Political Economics (indexing by WoS discontinued since 1990)

Studies in Conflicts and Terrorism

Topics in Macroeconomics

Venture Capital

Sources indexed only by Web of Science

Journal of the European Economic Association

Politikon

Swiss Political Science Review 